\title{
Mondor's Disease: A Rare Cause of Chest Pain
}

\author{
Jorge Miguel Bastos Mendes ${ }^{1}$, João Filipe Ferreira Gomes ${ }^{1}$, Lurdes Rovisco Branquinho ${ }^{1}$, Catarina Oliveira Carvalho², \\ Patrícia Filipa Afonso Pais Pacheco Mendes ${ }^{1}$, João Luís Carvalho Madaleno ${ }^{1}$ \\ ${ }^{1}$ Centro Hospitalar e Universitário de Coimbra, Faculdade de Medicina da Universidade de Coimbra, Coimbra, Portugal \\ ${ }^{2}$ USF Novo Norte, Arouca, Portugal
}

Received: 04/09/2020

Accepted: 20/09/2020

Published: $23 / 11 / 2020$

How to cite this article: Bastos Mendes JM, Ferreira Gomes JF, Rovisco Branquinho L, Oliveira Carvalho C, Pacheco Mendes PFAP, Carvalho Madaleno JL. Mondor's disease: a rare cause of chest pain. EJCRIM 2020;7: doi:10.12890/2020_001984.

Conflicts of Interests: The Authors declare that there are no competing interests.

This article is licensed under a Commons Attribution Non-Commercial 4.0 License

\section{ABSTRACT}

Introduction: Chest pain is a very frequent reason for seeking medical care. When there is no obvious cause, patients are sometimes subjected to tests and treatments that may be unnecessary and potentially harmful. Mondor's disease is a rare but usually benign and self-limited entity characterized by thrombophlebitis in a specific region.

Case report: We report the clinical case of a 51-year-old man admitted to the emergency department with a 24-hour history of left chest pain with no other symptoms. Physical examination revealed a palpable subcutaneous cord-like structure that ultrasound confirmed to be thrombophlebitis of a superficial vein in the mammary region. Secondary causes were ruled out, and the condition resolved with ibuprofen and the application of local ice.

Discussion: Mondor's disease can be associated with neoplasms, trauma or hyperviscosity states, but it is mostly idiopathic. Usually, it resolves completely in 4-8 weeks without specific treatment. Because this infrequent diagnosis mainly relies on clinical findings, it is important that clinicians can recognize the syndrome.

\section{LEARNING POINTS}

- Mondor's disease is a rare but benign disease, with no proof that specific treatment, such as anticoagulation, is beneficial.

- It may be secondary to underlying disease as malignancy, vasculitis, trauma or hyperviscosity states, which should be excluded.

- Treatment in the majority of the cases is symptomatic, but if it is secondary Mondor's disease, the underlying problem should be investigated. Physicians should be aware of this condition in order to address patient concerns and avoid unnecessary treatments or investigations.

\section{KEYWORDS}

Mondor, thrombophlebitis, chest pain

\section{CASE DESCRIPTION}

A 51-year-old man was admitted to the emergency department with a 24-hour history of left chest pain and tenderness in the left pectoralis major region and progressive worsening despite acetaminophen. He denied any trauma, injury or intensive physical activity and had no history of dyspnoea, fever, chills or other symptoms. The patient reported a history of bipolar disorder for which he was taking sodium valproate $500 \mathrm{mg}$ twice a day and alprazolam $1 \mathrm{mg}$ at bedtime. Physical examination revealed a palpable subcutaneous cord-like structure extending from the parasternal region to the proximal region of the left arm (Fig. 1). He also had redness and oedema along this structure with pain triggered by palpation. Blood tests only showed a slight increase in C-reactive protein and in leucocytes. The ultrasound revealed a tubular structure filled with hypoechogenic material corresponding to thrombophlebitis of a superficial vein in the mammary region, associated 
with hyper-reflectivity of the surrounding fat suggesting inflammation (Fig. 2). The patient was treated with ibuprofen and the application of local ice with a favourable evolution. An extensive study was conducted to exclude secondary causes. The thrombophlebitis resolved after 4 weeks without any specific treatment. After 6 months of follow-up, the patient remains without thrombophlebitis recurrence and without identified secondary causes.

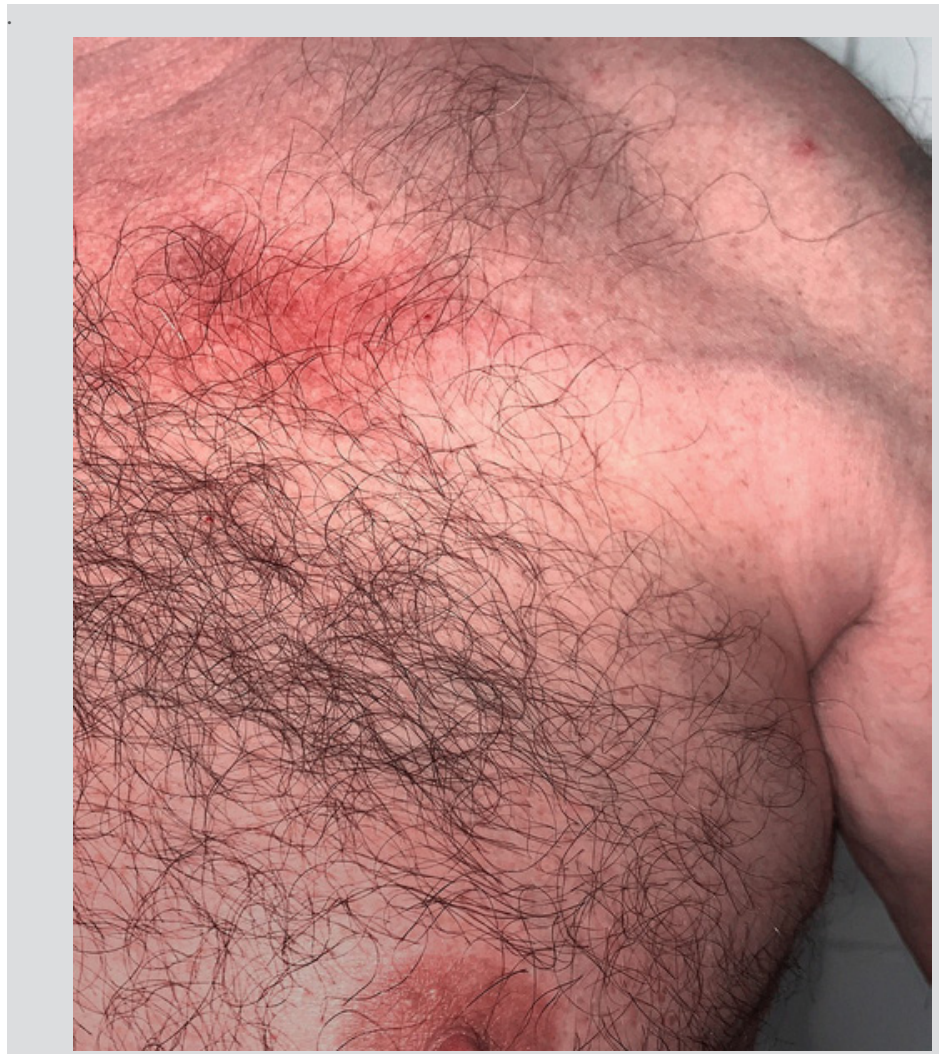

Figure 1. Cord-like thrombophlebitis of a left thoracic superficial vein with surrounding erythemax

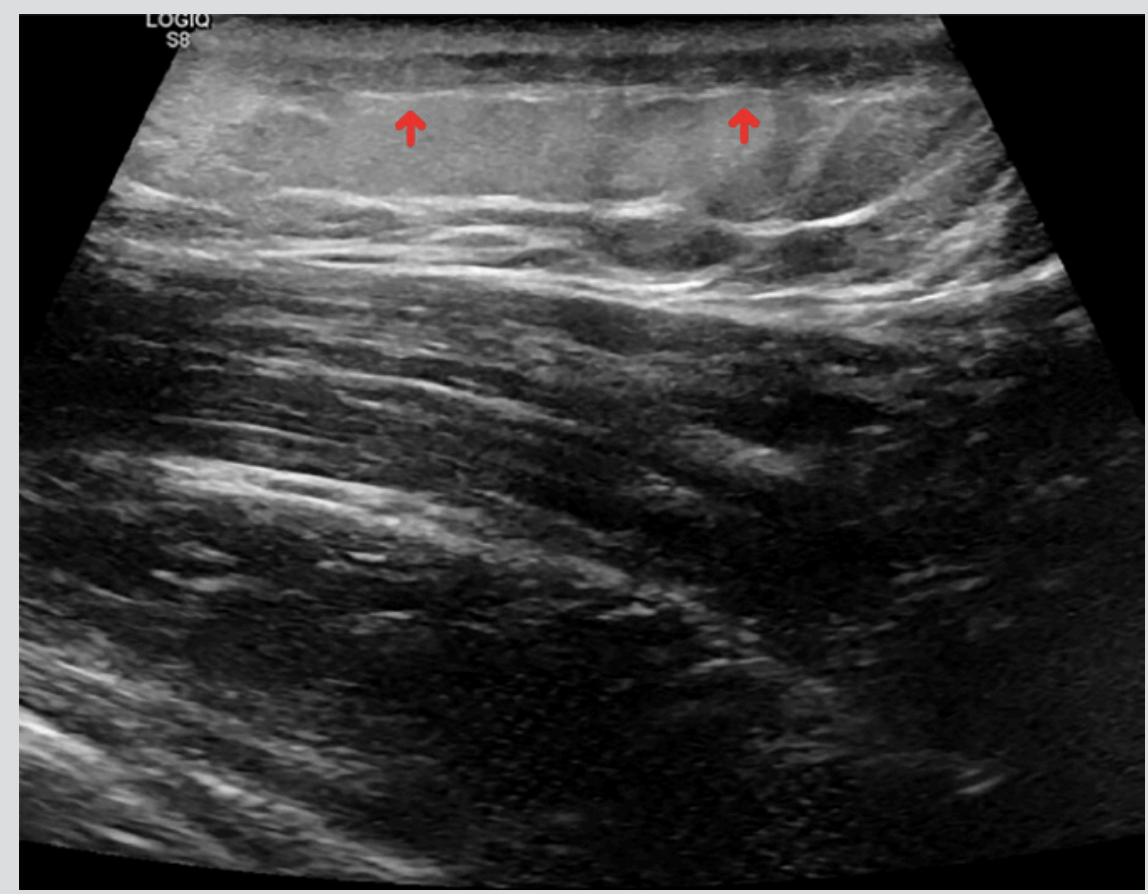

Figure 2. Ultrasound image showing thrombophlebitis of a superficial vein, associated with hyper-reflectivity of the surrounding fat suggesting inflammation 


\section{DISCUSSION}

Chest pain is one of the most frequent reasons for seeking medical care. When there is no obvious cause, patients are sometimes subjected to tests and treatments that may be unnecessary and potentially harmfu' ${ }^{[1]}$. Mondor's disease is a rare but usually benign and self-limited entity ${ }^{[2-5]}$. It is characterized by pain, oedema, erythema and increased temperature in a specific region where it is possible to feel a subcutaneous cord-like structure caused by thrombophlebitis and/or lymphangitis ${ }^{[2,3]}$. The first reported cases date back to 1850 , but the first detailed description of a case series was only published in 1939 by Henri Mondor ${ }^{[2]}$. The report described cases of thrombophlebitis in the anterolateral thoracic region, but later reports also described cases in the axillary region, also known as axillary web syndrome, and penis, also known as penile Mondor's disease ${ }^{[2,3]}$. Due to its rarity, the disease is seldom studied and remains poorly understood. Some studies report an incidence of $0.07-0.96 \%$ and a significantly higher frequency in women (9-14 cases in females for each case in males) ${ }^{[2]}$. Although it can be associated with neoplasms (particularly of the breast), trauma or hyperviscosity states, it is mostly idiopathic and usually has a benign course with complete resolution in 4-8 weeks without specific treatment. Prophylactic or intermediate doses of low-molecularweight heparin and subcutaneous administration of fondaparinux have been proposed but remain controversial due to the paucity of clear evidence. The usual treatment is application of local ice and non-steroidal anti-inflammatory drugs ${ }^{[2,3]}$.

Our patient had a normal clinical presentation of Mondor's disease. Because this infrequent diagnosis mainly relies on clinical findings, it is important that clinicians can recognize the syndrome.

\section{REFERENCES}

1. Bruno RR, Donner-Banzhoff N, Söllner W, Frieling T, Müller C, Christ M. Interdisziplinäre Versorgung akuter Thoraxschmerzen. Dtsch Arztebl Int 2015;112(45):768-780.

2. Amano M, Shimizu T. Mondor's disease: a review of the literature. Intern Med 2018;57(18):2607-2612.

3. Suganthan N, Ratnasamy V. Mondor's disease - a rare cause of chest pain: a case report. J Med Case Rep 2018;12(1):10-12.

4. Vijayalakshmi AA, Anand S. Mondor's disease. N Engl J Med 2017;376(23):e47.

5. Ito H, Ishibashi S, Kaburagi T. Mondor's disease. Intern Med 2019;58(12):1805-1805. 